\title{
Progress towards eliminating iodine deficiency in South Africa
}

\author{
${ }^{1}$ Jooste PL, ${ }^{2}$ Zimmermann MB \\ Nutritional Intervention Research Unit, Medical Research Council, Cape Town, South Africa \\ ${ }^{2}$ Human Nutrition Laboratory, ETH Zürich, Switzerland, and Division of Human Nutrition, Wageningen University, Wageningen, The Netherlands
} Correspondence to: Dr Pieter Jooste, e-mail: pieter.jooste@mrc.ac.za

\begin{abstract}
Before the introduction of salt iodisation in 1954, South Africa was one of the many countries of the world with a lack of iodine in most of its territory and hence there was a need for a salt iodisation programme. The understanding of the iodine situation in South Africa, the basics of iodine nutrition and progress toward eliminating iodine deficiency internationally and in South Africa are reviewed in this paper. Voluntary salt iodisation in the country at 10-20 ppm introduced in 1954 failed to eliminate endemic goitre and iodine deficiency. In contrast, considerable progress has been achieved in South Africa in eliminating iodine deficiency by introducing mandatory iodisation of table salt at 40-60 ppm in 1995. A 1998 survey showed that optimal iodine nutrition was achieved nationally and in seven of the nine provinces, with more than adequate iodine intake in two provinces. At that time, $86.4 \%$ of households used iodised salt and $62.4 \%$ used adequately iodised salt that contained more than $15 \mathrm{ppm}$ of iodine, with low coverage rates $(<50 \%)$ in the three northern provinces (Limpopo, Mpumalanga and North West). Closer collaboration between the South African lodine Deficiency Disorders Network and the salt industry resulted in improved accuracy of salt iodisation. Knowledge of iodine nutrition amongst adults is low, particularly in low socioeconomic households, leading to the vulnerability of these groups to obtain non-iodised salt for cooking via unconventional sources. In South Africa a sound scientific data base should be used to maintain the strengths of the national salt iodisation programme and improve on any aspects of the programme in need of attention.
\end{abstract}

S Afr J Clin Nutr 2008;21(1):08-14

\section{Basics of iodine nutrition}

lodine, one of the trace elements essential to human and animal health, is present in uneven and mostly insufficient quantities in the environment around the globe. An ecological cycle starting with iodine volatising from the ocean and repleting the soil by rain only partially replaces lost iodine. ${ }^{1}$ Animal and plant foods produced on soil with low iodine content contain very little or no iodine. Hence there is a need for adding iodine to the food chain through fortification, supplementation and/or dietary diversification to meet the iodine needs of humans in most countries of the world.

To maintain a sufficient iodine status, the World Health Organization (WHO), the United Nations Children's Fund (UNICEF) and the International Council for Control of lodine Deficiency Disorders (ICCIDD) recommend that the daily iodine intake should be $90 \mu \mathrm{g}$ for preschool children ( 0 to 59 months), $120 \mu \mathrm{g}$ for children of 6 to 12 years and $150 \mu \mathrm{g}$ for adults (above 12 years). ${ }^{2}$ The recommendation for pregnant and lactating women has recently been increased to $250 \mu \mathrm{g}$ per day. The richest natural source of iodine is sea food. Iodine may also occur in small amounts in different plants grown on iodinerich soil, but these amounts generally vary at low concentrations. In the USA and Europe, bread contains significant amounts of iodine due to iodised salt being used in the baking process, and in some countries cleansers containing iodine are used in the dairy industry resulting in an increase in the iodine content of milk.
Dietary iodine is reduced to iodide and is rapidly and almost completely absorbed (>90\%) in the gut. ${ }^{3}$ The uptake of circulating iodide by the thyroid depends on the iodine status of the individual. When the iodine status of an individual is optimal, less than $10 \%$ of the absorbed iodine will be taken up, whereas more than $80 \%$ is absorbed in iodine-deficient individuals. ${ }^{4}$ Under optimal conditions the human body contains 15 to $20 \mathrm{mg}$ of iodine, of which about $80 \%$ is stored in the thyroid gland. The amount of iodine stored in the thyroid may fall below $20 \mu \mathrm{g}$ in chronic iodine deficiency. Following the turnover of thyroid hormones, which have a circulating half-life of a few days, the iodine that is liberated re-enters the plasma iodine pool and may be taken up again by the thyroid or excreted by the kidneys. Ultimately more than $90 \%$ of iodine is excreted in the urine, making urinary iodine concentration a good indicator of iodine status and consumption.

\section{The iodine deficiency disorders}

lodine is an essential substrate for the synthesis of the two thyroid hormones, thyroxine (T4) and triiodothyronine (T3). When the physiological requirements of iodine are not met, thyroid hormone synthesis is impaired, resulting in hypothyroidism and a host of functional and developmental abnormalities collectively called the iodine deficiency disorders (IDDs) (Table I). ${ }^{2,5}$ These IDDs include thyroid function abnormalities, endemic goitre, mental retardation, cretinism, reproductive failure, and perinatal and infant mortality. The most damaging disorder resulting from iodine deficiency is 
Table I: The iodine deficiency disorders, by age group ${ }^{2,5}$

\begin{tabular}{|l|l|}
\hline Physiological groups & Health consequences of iodine deficiency \\
\hline All ages & Goitre \\
\hline & Hypothyroidism \\
\hline Increased susceptibility of the thyroid gland to \\
nuclear radiation
\end{tabular}

irreversible mental retardation occurring during the critical period from the foetal stage until the third month after birth.

Due to salt iodisation programmes worldwide the extreme manifestations of iodine deficiency are becoming increasingly uncommon. However, of major public health concern is the continued iodine deficiency in many countries leading to subtle degrees of mental impairment, poor school performance, reduced intellectual ability and impaired work capacity. Two meta-analyses reported a reduction of 12.5 to $13.5 \mathrm{IQ}$ points in iodine-deficient children. ${ }^{6,7}$ In South Africa, lower language exam marks were reported in goitrous children compared to non-goitrous children before the introduction of mandatory salt iodisation. ${ }^{8}$ Cognitive impairment appears to be at least partially reversible as shown in a recent clinical trial in 10 to 12 year old moderately iodine-deficient Albanian children who received $400 \mathrm{mg}$ of iodine as oral iodised oil or placebo. lodine treatment significantly improved information processing, fine motor skills, and visual problem solving compared to placebo in these children. ${ }^{9}$

Earlier cross-sectional studies reported equivocal findings on the relationship between iodine and growth, and some reported modest positive correlations. However, a recent study reported that access to iodised salt was related to increased birth weight and weight-forage of infants in five Asian countries. ${ }^{10}$ In school-age iodine-deficient children, supplementation of iodine in controlled trials increased insulin-like growth factor (IGF)-1 and insulin-like growth factor binding protein (IGFBP)-3 and improved somatic growth. ${ }^{11}$

\section{Assessment of iodine status}

Because the whole field of iodine nutrition is intimately linked to the supply of adequately iodised salt to the consumer, assessing the iodine status of a population should include both process and impact indicators. ${ }^{2}$ Factors influencing the process of supplying iodised salt to the consumer, which starts at the iodisation site and continues to the consumption stage, are assessed in terms of the process indicators. Examples include the assessment of the iodine content of salt at the point of production, retail and household levels, estimating the coverage of the percentage households using iodised $(>0 \mathrm{ppm}$ iodine) or adequately iodised (>15 ppm iodine) salt, determining the iodine content of processed foods, and assessing the level of knowledge regarding iodine nutrition amongst the adult population.

Impact indicators, also called outcome indicators, assess the effect of iodine consumption, usually measured in women and children. Urinary iodine is the most useful impact indicator because the rapid turnover of iodine in the body reflects recent changes in iodine intake. Because of considerable day-to-day variation in urinary iodine in individuals, the assessment of iodine status is done on groups of at least 40 to 50 individuals. The diagnosis is therefore a group diagnosis, not an individual one, based on the median urinary iodine concentration of the group. The cut-off levels and interpretation of iodine status are provided in Table II. ${ }^{2}$

Table II: Epidemiological criteria for assessing iodine nutrition in a population based on median and/or range of urinary iodine concentrations ${ }^{2}$

\begin{tabular}{|c|c|c|}
\hline $\begin{array}{c}\text { Median urinary iodine } \\
\text { ( } \mu \mathrm{g} / \mathrm{L})\end{array}$ & lodine intake & lodine nutrition \\
\hline \multicolumn{3}{|c|}{ School-aged children } \\
\hline$<20$ & Insufficient & Severe iodine deficiency \\
\hline 20-49 & Insufficient & Moderate iodine deficiency \\
\hline $50-99$ & Insufficient & Mild iodine deficiency \\
\hline $100-199$ & Adequate & Optimal \\
\hline 200-299 & More than adequate & $\begin{array}{l}\text { Risk of iodine-induced } \\
\text { hyperthyroidism in susceptible } \\
\text { groups }\end{array}$ \\
\hline$>300$ & Excessive & $\begin{array}{l}\text { Risk of adverse health } \\
\text { consequences (iodine-induced } \\
\text { hyperthyroidism, autoimmune } \\
\text { thyroid disease) }\end{array}$ \\
\hline \multicolumn{3}{|c|}{ Pregnant women } \\
\hline$<150$ & Insufficient & \\
\hline $150-249$ & Adequate & \\
\hline $250-499$ & More than adequate & \\
\hline$\geq 500$ & Excessive & \\
\hline \multicolumn{3}{|c|}{ Lactating women ${ }^{b}$} \\
\hline$<100$ & Insufficient & \\
\hline$\geq 100$ & Adequate & \\
\hline \multicolumn{3}{|c|}{ Children less than 2 years old } \\
\hline$<100$ & Insufficient & \\
\hline$\geq 100$ & Adequate & \\
\hline
\end{tabular}

a The term "excessive" means in excess of the amount required to prevent and control iodine deficiency. ${ }^{b}$ In lactating women, the figures for median urinary iodine are lower than the iodine requirements because of the iodine excreted in breast milk.

The thyroid size of children aged 6 to 12 years has been used as biological marker of iodine deficiency for many years, but its usefulness is limited because the thyroid size regresses slowly after increasing the iodine intake in salt iodisation programmes, ${ }^{12,13}$ and results need to be interpreted cautiously. Thyroid size determined by palpation is graded as Grade 0 when the thyroid is not palpable, Grade 1 when it is palpable but not visible and the size of the lobe is bigger than the size of the end digit of the thumb of the 
individual being examined, and Grade 2 when the thyroid is palpable and visible when the neck is in the normal position. When more than $5 \%$ of school age children have enlarged thyroids, goitre is endemic. Prevalence of goitre from $5 \%$ to $19.9 \%, 20 \%$ to $29.9 \%$ and more than $30 \%$ indicate mild, moderate or severe degrees of IDDs respectively.

Large interobserver variation usually occurs when the thyroid size is determined by palpation. Ultrasonography is a more precise investigation when compared with palpation and is safe for measuring thyroid volume. It is particularly useful when the prevalence of visible goitres is small and in monitoring iodine control programmes where thyroid volume is expected to decrease over time. New international cut-off levels specific for age, gender and body surface area of 6 to 12 year old children are available for interpreting ultrasound data. ${ }^{14}$

Serum thyroid stimulating hormone (TSH) is a sensitive indicator in newborns because the newborn thyroid contains less iodine but has higher rates of turnover than adults. For this indicator to be useful, a universal screening system for newborn TSH is essential. TSH screening is only performed in the metropolitan areas of South Africa and is therefore not useful as an IDD indicator of the population. Another biochemical indicator, thyroglobulin, can be used in a complementary way to urinary iodine excretion in children and adults. A new thyroglobulin analytical method on dried blood spots from finger prick samples on filter paper makes this indicator useful under field conditions even in remote areas. ${ }^{15}$

\section{Progress in the elimination of IDDs}

\section{The international picture}

Since 1917, when Marine and Kimball first treated goitrous school girls with iodine tablets, ${ }^{16}$ and 1922, when Switzerland started the first salt iodisation programme, ${ }^{17}$ progress was slow in identifying and eliminating iodine deficiency until about 1990. At that time, Switzerland, some of the the Scandinavian countries, USA, Canada, Australia and Japan were the only iodine-sufficient countries. The ICCIDD was formed in 1985. Its long-term goal is to eliminate iodine deficiency globally. Deficiency elimination efforts by UNICEF, the WHO and ICCIDD gained enormous momentum through resolutions accepted at high-level meetings of the United Nations agencies in the early nineties, resolving to virtually eliminate iodine deficiency by the year 2000 .

Universal salt iodisation (USI) was adopted as the main long-term public health strategy to eliminate iodine deficiency. ${ }^{2}$ USI was defined as the strategy in which all salt for human and animal consumption is iodised according to the recommended levels. This strategy resulted in tremendous progress in improving accessibility to iodised salt. Although the goal of virtually eliminating IDDs by the year 2000 was not achieved, the WHO showed in 1999 that 3.3 billion people, about two-thirds of the total population of the 130 countries that had IDDs in 1990, had access to iodised salt at that time..$^{18}$ Progress had been the greatest in Africa, where control programmes existed in only a handful of countries prior to 1990. By contrast, progress has been slowest in the European Region, where only $27 \%$ of the population in at-risk areas consumed iodised salt and mild iodine deficiency persisted in several countries in Western Europe. Further east, in some Central Asian countries and in the Russian Federation, control programmes had collapsed and less than $5 \%$ of households were using iodised salt.
During the decade 1993 to 2003, the number of countries in which iodine deficiency was a public health problem decreased from 110 to 54 countries, ${ }^{19}$ and further decreased to 47 countries in 2007. ${ }^{20}$ Amongst the countries experiencing iodine deficiency were industrialised countries such as France ${ }^{21}$ as well as countries, such as Australia, which were experiencing a re-emerging of iodine deficiency due to inadequate salt iodisation programmes. ${ }^{22}$ The prevalence of low iodine intake correlated with the household coverage of iodised salt. The Americas had the highest percentage of households consuming iodised salt (90\%) in contrast to the European Region, which had the lowest percentage of households consuming iodised salt $(27 \%)$. Overall, one-third of the world's school-age children, and two billion of the general world population, are still exposed to an insufficient iodine intake.

Along with the shift towards iodine sufficiency in many countries, 29 countries had more than adequate or even excessive iodine intake in 2003. ${ }^{19}$ This number of countries further increased to 34 countries in $2007 .{ }^{20}$ It is thus clear that the improved salt iodisation programmes were accompanied by overcorrection of iodine levels in at least 34 countries, exposing susceptible groups to the possible risk of iodine-induced hyperthyroidism $(\mathrm{IIH})$. Despite the tolerance of the thyroid gland for iodine intakes of $1000 \mu \mathrm{g}$ of iodine per day or even more, ${ }^{3,23}$ a small number of people older than 40 years of age, living in iodine-deficient areas, with existing nodular goitre and who had been exposed to a sudden increase in iodine intake, are susceptible to developing $\mathrm{IH}$ in the next five to ten years. After this time, the occurrence of $\mathrm{IH}$ is expected to drop to below baseline level. ${ }^{24}$ Excessive iodine intakes usually result from over-iodised salt or processed food accompanied by poor monitoring practices.

\section{IDD in Africa}

According to the $\mathrm{WHO}^{25}$ and UNICEF databases, ${ }^{26}$ the iodine nutritional status and coverage of households consuming iodised salt vary considerably from country to country in Africa. At the one extreme some countries like Ethiopia, Gambia, Ghana, Mauritania, Sudan and Mozambique are still iodine deficient, while at the other end of the spectrum countries like the Democratic Republic of the Congo, Rwanda, Uganda and Zimbabwe are experiencing iodine over-nutrition. Both the iodine deficiencies and excesses seen in Africa are due to country salt iodisation programmes either providing insufficient or excessive amounts of iodine.

Failing salt iodisation programmes are mostly related to weak or absent legislation, ${ }^{27}$ insufficient monitoring, famine, conflict or political instability. ${ }^{28}$ lodine excesses in some African countries are mostly related to legislation requiring high iodine concentrations of up to $100 \mathrm{ppm}$ of iodine in salt to compensate for potential iodine losses from salt under hot and humid transport and storage conditions, over-iodisation at the production site and poor monitoring of iodine in salt. The WHO, UNICEF and ICCIDD recommend that salt should be fortified at a concentration of 20 to $40 \mathrm{ppm}$ at the production site. ${ }^{2}$ Examples of over-supply are the excessive increments of iodine in salt supplied to previously iodine-deficient areas in Zimbabwe and the Demographic Republic of the Congo, which resulted in an increased risk of $\mathrm{IH} .^{29}$

South Africa is one of the African countries with an optimal iodine nutritional status, as shown in a 1998 national survey.$^{30} \mathrm{~A}$ number of African countries such as Nigeria have also succeeded in achieving optimal iodine nutrition. ${ }^{31}$ After an external evaluation of their salt 
iodisation programme, Nigeria was recently recognised as the first African country that has successfully eliminated iodine deficiency. Whereas national surveys conducted before 1998 used total goitre rate as the main indicator of IDD, the emphasis has since shifted towards using the median urinary iodine concentration as the main indicator. ${ }^{2,19}$

\section{lodine nutrition in South Africa}

\section{Historical perspective}

Endemic goitre was reported for the first time in South Africa in the Langkloof area of the Eastern Province in 1927.32 Subsequent investigations found widespread endemic goitre during the following years, culminating in the appointment of the South African Goitre Research Committee under the auspices of the Medical Faculty of the University of Pretoria in 1948. On recommendation of this committee, optional iodisation of salt with potassium iodate was legally introduced in South Africa at a level of 10-20 ppm of iodine in 1954. For the following four decades virtually no new goitre or iodine information was produced in the country and the Goitre Research Committee was disbanded.

Compared to the early studies,$^{32}$ optional iodisation of salt improved the goitre rates in children in four Langkloof communities, but did not solve the problem of endemic goitre or of iodine deficiency. ${ }^{33}$ Goitre rates varied from $14 \%$ to $30 \%$ and the median urinary iodine concentrations indicated mild to severe iodine deficiency prevailing in these four communities in 1995, before the introduction of mandatory iodisation. Generally, the reasons for optional iodisation failing to eliminate iodine deficiency were a) only about a third of table salt produced in South Africa was iodised; b) unequal distribution of iodised salt favoured urban areas; c) price-sensitive rural and low income consumers used cheaper non-iodised salt brands; and d) there was a low awareness of the benefits of iodised salt. ${ }^{34}$ Endemic goitre and iodine deficiency thus remained a public health problem in South Africa in the 1990s. ${ }^{8,33,35}$

\section{Impact of mandatory iodisation of salt}

Against the background of persistent iodine deficiency in the country, the existence of iodine deficiency in all South Africa's neighbouring countries at that time, ${ }^{36}$ the international goal to virtually eliminate iodine deficiency by the year 2000 , and the support and encouragement from UNICEF, mandatory iodisation of table salt at a higher concentration than in the past was introduced in December 1995 in South Africa. The revised legislation stipulated that 40-60 ppm of iodine in the form of potassium iodate must be added to all table salt. This regulation does not apply to salt being used in the production of processed foods or to agricultural salt. As a compromise to accommodate technical difficulties experienced in the salt iodisation industry to achieve the required iodine level, the regulation was revised in 2006 to widen the required iodisation range to $35-65 \mathrm{ppm}$.

Remarkable progress in the elimination of iodine deficiency was seen in South Africa since the introduction of mandatory iodisation at an elevated iodine concentration. The mean iodine content of table salt at the retailer level increased significantly from 14 to $33 \mathrm{ppm}$ in one year, but was accompanied by wide variation in iodine concentrations. ${ }^{37}$ As a consequence a dramatic shift occurred, also within one year, in the distribution of urinary iodine values from deficient to sufficient concentrations in four communities in the Langkloof area. ${ }^{12}$ The goitre rates in these children, measured by palpation, remained unchanged after a year, confirming the slow regression of the thyroid size after increasing the iodine intake observed in the Ivory Coast. ${ }^{38}$ This data also indicated that goitres measured by palpation may not be appropriate in the short-term evaluation of changes in salt iodisation programmes.

Median urinary iodine concentrations in a national IDD survey $(\mathrm{n}=8524)$ conducted in 1998 on primary school children showed that optimal iodine nutrition (median urinary iodine 100-199 $\mu \mathrm{g} / \mathrm{L}$ ) existed at the national as well as at the provincial level in seven of the nine provinces, with the other two provinces displaying more than adequate iodine intake. ${ }^{30}$ Based on urinary iodine concentrations, $16 \%$ of 179 schools included in the study had indications of persisting iodine deficiency. High goitre rates assessed by palpation, ranging from $20 \%$ to $68 \%$, were observed in a sub-sample of 49 schools. However, there is doubt about the accuracy of thyroid measurement in this survey, as normal thyroid sizes were found in a follow-up study using ultrasonography in one of these schools. ${ }^{39}$ The survey nevertheless showed that aggregated national and provincial urinary iodine data may mask pockets of persisting iodine deficiency, as was later confirmed in rural schools in the Limpopo province. ${ }^{40}$

In the 1998 national survey a median urinary iodine intake of $242 \mu \mathrm{g} / \mathrm{L}$ was found in children of the Northern Cape province. This value, indicating more than adequate iodine intake in this province, most likely resulted from a combination of the salt iodisation programme and abundant iodine in the environment as reflected by high iodine concentrations in the drinking water of some Northern Cape towns. ${ }^{41}$ In addition, high goitre rates were observed in towns with excessive amounts of fluorine in the drinking water.

\section{Process indicators}

Since the introduction of mandatory salt iodisation in South Africa, several process indicators have been investigated, mostly on a national scale. These indicators are dealt with in more detail and more or less chronologically below.

\section{lodine in household salt}

In the same year as the 1998 national IDD survey, another national survey on a nationally and provincially representative sample of 2 043 households was carried out to investigate the iodine content of household salt by means of the titration method. ${ }^{42}$ This was probably the first national survey using the quantitative titration method instead of the rapid test-kit method to estimate the iodine content of household salt. The data showed that $95.4 \%$ of households in South Africa used salt regularly and $2.9 \%$ occasionally, providing confirmation that salt is an effective fortification vehicle penetrating virtually all households in the country.

Coverage data from this study showed that $86.4 \%$ of households used salt containing any amount of iodine and $62.4 \%$ used adequately iodised salt containing $15 \mathrm{ppm}$ or more iodine, with considerable variation amongst the provinces. The Eastern Cape province with a coverage of $77 \%$ of households came closest to the international goal of $90 \%$ of households using adequately iodised salt, ${ }^{2}$ while less than half of households in the three northern provinces (Limpopo, Mpumalanga and North West) used adequately iodised salt. One of the reasons for this weakness in the salt iodisation programme was the substantial percentage of households in the three northern provinces 
using non-iodised repackaged agricultural salt or non-iodised salt obtained directly from the producers. Another likely reason was under-iodisation of salt occurring at the production sites.

In an African context, the South African coverage rates had room for improvement. In countries such as Sudan, Mauritania, GuineaBissau and Gambia, coverage is less than $10 \%$, whereas in Burundi, Kenya, Nigeria, Tunisia, Uganda and Zimbabwe it is more than $90 \%{ }^{26}$ The complication in South Africa was that rural people at the lower end of the socioeconomic spectrum were more likely to suffer the consequences of using under-iodised salt because more of them used agricultural salt, and more of them used coarse salt that contained less iodine than fine salt, than did people in the higher socioeconomic categories. ${ }^{42}$

\section{Iodine in retailer salt:}

Although not appropriate for law enforcement, monitoring the iodine concentration in retailer salt provides a quick and easy sign of the accuracy of the iodisation process at the production level. A follow-up study of the iodine in retailer salt in 48 sentinel towns situated in three of the nine provinces of the country shortly before the introduction of mandatory iodisation at an elevated iodine concentration, and again after one, three and five years, found a relapse in the long term after an initial increase in iodine concentration. ${ }^{37,43}$ In this study the mean iodine concentration increased from $14 \mathrm{ppm}$ to $33 \mathrm{ppm}$ after one year and then to $42 \mathrm{ppm}$ after three years, but returned to the lower levels of $33 \mathrm{ppm}$ after five years. This was a clear public health warning to assess the accuracy of salt iodisation at all the production sites in South Africa.

\section{lodine in salt at the production sites}

In view of the substantial under-iodisation as well as the considerable variation in iodine concentration observed in retail and household salt, ${ }^{37,42,43}$ the iodine content of salt and the knowledge regarding iodine nutrition of managers were assessed at all the iodised-salt production sites in the country in 2001. Of the 204 salt samples collected at 12 producers and analysed by means of the titration method, $34.8 \%$ contained less than 20 ppm of iodine and $57.9 \%$ less than the legally required amount of $40-60 \mathrm{ppm}$. Additionally, shortcomings existed in the managers' knowledge of health aspects of salt iodisation and at least a third of the producers, mostly small and medium-sized producers, had no means of internal monitoring. ${ }^{44}$

In response to the need for support on iodine matters, the South African IDD Network, established in 2002 as a coalition of active role-players in the salt iodisation programme, ${ }^{45}$ initiated an iodine educational programme for salt producers. This programme consisted of personal visits and feedback on their results to the salt producers, regular mailings of literature on iodine nutrition and a workshop to strengthen their commitment to salt iodisation. Re-assessment of the producers' salt in 2005 showed a marked shift in the distribution of iodine values towards higher concentrations, with markedly less under-iodisation accompanied by an increase in over-iodisation (Figure 1) ${ }^{46}$ The under-iodisation originated largely from producers not using titration or an equivalent quantitative method for internal quality control, and the over-iodisation resulted from overcorrection of the iodine concentration during the iodisation process and, again, insufficient monitoring.

To assist the salt industry in overcoming these problems of overand under-iodisation, the South African IDD Network assisted salt
Figure 1: Relative distribution of the percentage of South African producers' salt samples in the different iodine concentration categories in 2001 and 2005

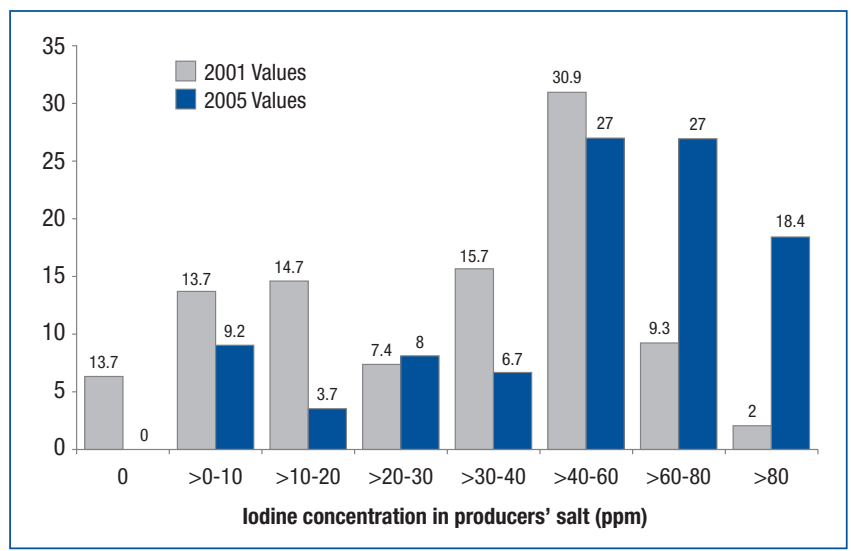

producers without facilities to set up titration laboratories at their salt plants, and reviewed the analytical methodology of the other producers to standardise and optimise the laboratory methods in 2006 and 2007. Since all salt producers are currently equipped and trained to determine the iodine concentration of salt quantitatively, and external monitoring of the accuracy of salt iodine analyses was done at the end of 2007, it is believed that the accuracy of salt iodisation will improve in the whole industry.

\section{lodine in processed foods}

Table salt is not the only vehicle for iodine. Elsewhere in the world iodine is also added to salt for the bread-baking industry, animal food, processed meat, fish sauce, drinking or irrigation water. lodine in milk in the USA and Europe is derived from iodophors, i.e. iodine-containing detergents used in the dairy industry. ${ }^{47,48}$ It is not mandatory to use iodised salt for the production of processed food in South Africa, and most producers use non-iodised salt in their products to prevent unwanted effects of iodine on the properties of their product, for health reasons and financial considerations. ${ }^{49}$ Despite these fears, substantial amounts of iodine, namely 39-69 ppm, were found in the salt of one-third (4 out of 12) of manufactures of bread, margarine and flavourants of salty snacks in South Africa. Processed foods may therefore provide variable but significant amounts of iodine to the food chain in South Africa.

\section{Sources of household salt}

As in many other countries, marketing of non-iodised salt through unconventional distribution channels is one of the factors weakening the national salt iodisation programme in South Africa. In a national survey it emerged that $78 \%$ of households obtain their table salt from typical food stores distributing iodised salt. ${ }^{50}$ However, in the nine provinces between $8 \%$ and $37 \%$ of households used unconventional sources to obtain their (mainly non-iodised) household salt. These alternative sources include distributors of agricultural salt, small general dealer shops (called spaza shops) in peri-urban and rural townships, street vendors and salt sachets placed in the packaging of maize meal bags. Countrywide around $30 \%$ of low socioeconomic households obtain their salt from unconventional sources compared to less than $5 \%$ in high socioeconomic households, emphasising the vulnerability of low socioeconomic groups to the use of non-iodised salt and the threat of unconventional distribution channels to the salt iodisation programme. 


\section{Knowledge of iodine nutrition}

Knowledge of iodine nutrition is a process indicator often neglected in salt iodisation programmes because of the usual emphasis placed on iodine in salt and its impact on iodine and goitre status. From the limited information available on this topic, it appears that the knowledge level of iodine nutrition varies from very low in a country such as India ${ }^{51}$ to levels where people are well informed, such as in Iran. ${ }^{52}$ In Iran, literate women were more likely to use iodised salt in the household than illiterate women.

In South Africa, in a national study assessing the knowledge of iodine nutrition of 2164 adults, representing the full range of socioeconomic strata, only $15 \%$ of respondents correctly identified iodised salt as the primary dietary source of iodine, $16 \%$ knew the thyroid gland needs iodine for its functioning, and a mere $4 \%$ considered brain damage as the most important health consequence of iodine deficiency. ${ }^{53}$ Knowledge was even poorer in low socioeconomic households where respondents were considerably less well-informed about aspects of iodine nutrition compared to high socioeconomic households. The low level of knowledge about iodine nutrition amongst South African adults suggests that the international message about brain damage resulting from iodine deficiency has not been conveyed successfully at the consumer level in the country. Neither is it likely that consumers will choose or demand iodised salt for the benefit of children and women.

Moreover, a number of factors such as the under-iodisation of salt by producers, the domestic use of non-iodised agricultural salt, consumers obtaining non-iodised cheap salt directly from producers, informal repackaging for household use of non-iodised salt, and a variety of other malpractices, may weaken mandatory salt iodisation programmes in any country. A thorough knowledge of iodine nutrition and of IDDs, from the programme manager to the consumer, is likely to counteract these limiting factors to a large extent. These are also the factors responsible for not achieving the goal of $90 \%$ of households using adequately iodised salt. Improving the knowledge levels of all involved in the supply of iodised salt to the consumer may bring us closer to the goal, and may sustain a successful programme.

Intervention improved the knowledge level of South African salt producers ${ }^{46}$ but a complicating factor was the turnover in managers seen in the salt industry. Over time a turnover in all role-players is inevitable, making continuous iodine education indispensable. One of the biggest stumbling blocks in the implementation of a successful national salt iodisation programme is the inadequate education and lack of iodine knowledge of those involved. Dunn refers to inadequate education as one of the seven deadly sins in confronting endemic iodine deficiency. ${ }^{54}$ For an iodisation programme to be successful and sustainable, he emphasises that it is essential for all role-players involved to have a thorough knowledge of the importance of iodine deficiency, its consequences, and the means for its sustainable correction.

\section{Challenges for the salt iodisation programme in South Africa}

South Africa is on the verge of eliminating iodine deficiency. While national and provincial median urinary iodine values indicate iodine sufficiency, the available data point to gaps in both the process as well as the impact sides of the iodine nutritional field. About a third of the world population,,$^{20}$ and just more than a third of the South African population $^{42}$ still need to be reached with adequately iodised salt, and the last portion is usually the most difficult to reach. Therefore, to achieve the international goal of eliminating iodine deficiency, the following challenges need to be addressed in South Africa while maintaining the successes of the past:

1 The household coverage of adequately iodised salt needs to be increased to $90 \%$ nationally and in all the provinces to reach those most in need of iodine. This could be achieved by assisting the salt industry to improve the accuracy of salt iodisation through improved internal quality control of the iodine content of salt at the production sites and by regular external monitoring of the iodine concentration in salt.

2 Another strategy to increase the coverage is to overcome or counteract the reasons for households using non-iodised salt. Examples are to iodise agricultural salt in areas where the practice of using non-iodised agricultural salt is common, ensure that religious groups distributing non-iodised salt convert to distributing only iodised salt, ensure that small general dealers, or spaza shops, in peri-urban and rural townships sell only iodised salt, and use iodised salt in sachets placed in maize meal bags.

3 The South African IDD Network and the health authorities should maintain close contact with the salt industry not only to monitor the iodine in salt, but particularly to strengthen the commitment of salt producers to salt iodisation through a mutual exchange of relevant information. This is of great importance in instances where changes in management occur.

4 In view of the apparent abundant iodine levels in the environment of the Northern Cape province and the more than adequate iodine status of the people, it is necessary to investigate the iodine status of the inhabitants to prevent an increased risk of iodine-induced hyperthyroidism.

5 No information is available on pregnant women in South Africa. The iodine status and needs of this vulnerable group thus need to be established.

6 The knowledge regarding iodine nutrition of salt producers, consumers, health staff, politicians, schoolchildren and pregnant women should be improved through a multisectoral approach.

7 Regular monitoring of process and impact indicators and reporting the information is a standard recommendation for sustaining a salt iodisation programme. In South Africa, external monitoring and quality control of the salt iodine analyses of salt producers should be formalised and structured to ensure regularity of such monitoring.

8 In terms of two World Health Assembly Resolutions adopted in 2005 and 2007, member countries, including South Africa, are obliged to report their IDD situation every three years to the WHO. ${ }^{55}$ The Department of Health, with the assistance of the South African IDD Network, should position itself to accurately report progress in the iodine nutritional status of the country to the WHO every three years.

South Africa is in a favourable position to have a sound scientific data base for identifying strengths and challenges of the national salt iodisation programme. The results of a recent national IDD survey are awaited in 2008 and should complement the recommendations of this review. Overall, we need to sustain the successes of the past, fine-tune the programme and fill the gaps to achieve the elimination of iodine deficiency. Then we need to vigorously guard against the trap of complacency which has led to the downfall of previously successful programmes. ${ }^{56}$ 


\section{References}

1. Hetzel B, ed. The story of iodine deficiency: An international challenge in nutrition. New York: Oxford University Press; 1991.

2. World Health Organization/United Nations Children's Fund/International Council for Control of lodine Deficiency Disorders (WHO/UNICEF/ICCIDD) Assessment of iodine deficiency disorders and monitoring their elimination. A guide for programme managers. 3rd edition. Geneva: WHO; 2007.

3. Institute of Medicine (IOM), Academy of Sciences, USA. Dietary reference intakes for vitamin A, vitamin $\mathrm{K}$, arsenic, boron, chromium, copper, iodine, iron, manganese, molybdenum, nickel, silicon, vanadium and zinc. Washington DC: National Academy Press; 2001.

4. Rousset BA, Dunn JT. Thyroid hormone synthesis and secretion. In: DeGroot LE, Hannemann G, eds, The thyroid and its diseases. Available http://www.thyroidmanager.org/ (Accessed 18/11/2007).

5. Delange F. The disorders induced by iodine deficiency. Thyroid 1994;4:107-28.

6. Bleichrodt N, Born MP. A meta-analysis of research on iodine and its relationship to cognitive development. In: Stanbury JB, ed. The damaged brain of iodine deficiency. New York: Cognizan Communication, 1994:195-200.

7. Qian M, Wang D, Watkins WE, Gebski V, Yan YQ, Li M, Chen ZP. The effects of iodine on intelligence in children: A meta-analysis of studies conducted in China. Asia Pacif J Clin Nutr 2005:14:32-42.

8. Benadé JG, Oelofse A, Van Stuijvenberg ME, Jooste PL, Weight MJ, Benadé AJS. Endemic goitre in a rural community of KwaZulu-Natal. S Afr Med J 1997;87:310-3.

9. Zimmermann MB, Connolly K, Bozo M, Bridson J, Rohner F, Grimci L. lodine supplementation improves cognition in iodine-deficient schoolchildren in Albania: A randomized, controlled, doubleblind study. Am J Clin Nutr 2006;83:108-14.

10. Mason JB, Deitchler M, Gilman A, Gillenwater K, Shuaib M, Hotchkiss D, Mason K, Mock N Sethuraman K. lodine fortification is related to increased weight-for-age and birthweight in children in Asia. Food Nutr Bull 2002;23:292-308.

11. Zimmermann MB, Jooste PL, Mabapa NS, Mbhenyane X, Schoeman S, Biebinger R, Chaouki N, Bozo M, Grimci L, Bridson J. Treatment of iodine deficiency in school-age children increases insulin-lik growth factor (IGF)-I and IGF binding protein-3 concentrations and improves somatic growth. J Clin Endocrinol Metab 2007:92:437-42.

12. Jooste PL, Weight MJ, Lombard CJ. Short-term effectiveness of mandatory iodization of table salt, at an elevated iodine concentration, on the iodine and goiter status of schoolchildren with endemic goiter. Am J Clin Nutr 2000;71:75-80.

13. Zimmermann MB, Hess SY, Adou P, Toresanni T, Wegmüller R, Hurrell RF. Thyroid size and goite prevalence after introduction of iodized salt: A 5-yr prospective study in schoolchildren in Côte d'lvoire. Am J Clin Nutr 2003:77:663-7.

14. Zimmermann MB, Hess SY, Molinari L, De Benoist B, Delange F, Braverman LE, Fujieda K, Ito Y, Jooste PL, Moosa K, Pearce EN, Pretell EA, Shishiba Y. New reference values for thyroid volume by ultrasound in iodine-sufficient schoolchildren: A WHO/NHD lodine Deficiency Study Group Report. Am J Clin Nutr 2004;79:231-7.

15. Zimmermann MB, De Benoist B, Corigliano S, Jooste PL, Molinari L, Moosa K, Pretell EA, Al-Dalla ZS, Wei Y, Zu-Pei C, Torresani T. Assessment of iodine status using dried blood spot thyroglobulin: Development of reference material and establishment of an international reference range in iodinesufficient children. J Clin Endocrinol Metab 2006:91:4881-7.

16. Carpenter KJ. David Marine and the problem of goiter. J Nutr 2005;135:675-80

17. Bürgi H, Supersaxo Z, Selz B. lodine deficiency diseases in Switzerland one hundred years after Theodor Kocher's survey: A historical review with some new goitre prevalence data. Acta Endocrino (Copenh) 1990;123:577-90

18. WHO, UNICEF, ICCIDD. Progress towards elimination of iodine deficiency disorders. Geneva, World Health Organization; 1999

19. Andersson M, Takkouche B, Egli I, Allen H, De Benoist B. Current global status and progress over the last decade towards the elimination of iodine deficiency. WHO Bull 2005;83:518-25.

20. De Benoist B, McLean E, Andersson M. Iodine deficiency in 2007: Global progress since 2003. Food Nutr Bull (in press).

21. Valeix P, Zarebska M, Preziosi P, Galan P, Pelletier B, Hercberg S. lodine deficiency in France. Lance 1999;353:1766-7

22. Li M, Eastman CJ, Waite KV, Ma G, Zacharin MR, Topliss DJ, Harding PE, Walsh JP, Ward LC, Mortime RH, Mackenzie EJ, Byth K, Doyle Z Are Australian children iodine deficient? Results of the Australian National Iodine Nutrition Survey. Med J Australia 2006:184:165-9.

23. Braverman LE. Iodine and the thyroid: 33 years of study. Thyroid 1994;4:351-6.

24. Bürgi $\mathrm{H}$, Kohler M, Morselli B. Thyrotoxicosis incidence in Switzerland and benefit of improved iodine supply. Lancet 1998;352:1034

25. De Benoist B, Andersson M, Egli I, Takkouche B, Allen H. Iodine status worldwide. WHO Global Database on lodine Deficiency. World Health Organization, Geneva; 2004.

26. UNICEF. The State of the World's Children 2007. Available www.unicef.org/nutrition/files/SOWC06 Table2.pdf (Accessed 7/12/2007).

27. Dunn JT. lodine nutrition in Africa. IDD Newsletter 2003;19:1-6.

28. Okosieme OE. Impact of iodination on thyroid pathology in Africa. J R Soc Med. 2006;99:396-401. 29. Delange F, De Benoist B, Alnwick D. Risks of iodine-induced hyperthyroidism after correction of iodine deficiency by iodized salt. Thyroid 1999;9:545-56.

30. Immelman R, Towindo T, Kalk WJ, Paiker J, Makuraj S, Naicker J, Omar S. Report of the South African Institute for Medical Research on the lodine Deficiency Disorder Survey of primary schoo learners for the Department of Health, South Africa. South African Institute for Medical Research; 2000

31. Egbuta J, Onyezili F, Vanormelingen K. Impact evaluation of efforts to eliminate iodine deficiency disorders in Nigeria. Public Health Nutr 2003;6:169-73.
32. Steyn DG, Kieser J, Odendaal WA, Malherbe MA, Snyman W, Sunkel W, Naude CP, Klintworth H, Fisher $E$. Endemic goitre in the Union of South Africa and some neighbouring territories. Report to the Department of Nutrition, Union of South Africa; 1955

33. Jooste PL, Weight MJ, Kriek JA. lodine deficiency and endemic goitre in the Langkloof area of South Africa. S Afr Med J 1997:87:1374-9.

34. Jooste PL, Marks AS, Van Erkom Schurink C. Factors influencing the availability of iodised salt in South Africa. S Afr J Food Sci Nutr 1995;7:49-52.

35. Kalk WJ, Paiker J, Van Arb MG, Pick W. Dietary iodine deficiency in South Africa. Surveys before the introduction of universal salt iodisation. S Afr Med J 1998:88:357-8.

36. Jooste PL, Benade AJS, Kavishe F, Sanders D. Does iodine deficiency exist in South Africa? S Af Med J 1995;85:1143-4.

37. Jooste PL, Weight MJ, Locatelli-Rossi L, Lombard CJ. Impact after one year of compulsory iodisation on the iodine content of table salt at retailer level in South Africa. Int J Food Sci Nut 1999;50:7-12.

38. Zimmermann MB, Hess SY, Adou P, Toresani T, Wegmüller R, Hurrell RF. Thyroid size and goiter prevalence after introduction of iodized salt: A 5-yr prospective study in schoolchildren in Côte d'Ivoire. Am J Clin Nutr 2003;77:663-7.

39. Jooste PL, Joubert E. The iodine and goitre status of primary schoolchildren near Worcester in the Western Cape. S Afr J Clin Nutr 2004;17:32-4.

40. Zimmermann MB, Jooste PL, Mabapa NS, Schoeman S, Biebinger R, Mushaphi LF, Mbhenyane X. Vitamin A supplementation in iodine-deficient African children decreases thyrotropin stimulation of the thyroid and reduces the goitre rate. Am J Clin Nutr 2007:86:1040-4.

41. Jooste PL, Weight MJ, Kriek JA, Louw AJ. Endemic goitre in the absence of iodine deficiency in schoolchildren of the Northern Cape province of South Africa. Europ J Clin Nutr 1999;53:8-12.

42. Jooste PL, Weight MJ, Lombard CJ. lodine concentration in household salt in South Africa. WHO Bull 2001;79:534-40.

43. Jooste PL. Monitoring the effect of introducing mandatory iodisation at an elevated iodine concentration on the iodine content of retailer salt after 1,3 and 5 years in South Africa. Int J of Food Sci Nutr 2004;55:555-9.

44. Jooste PL. Assessment of the iodine concentration in table salt at the production stage in South Africa. WHO Bull 2003;81:517-21.

45. Jooste PL. The birth of a National IDD Coalition in South Africa. IDD Newsletter 2002:18:22-3.

46. Jooste PL. The iodine content of table salt at the production sites in South Africa in 2005. MRC Technical Report, Medical Research Council, Parow, Cape Town; June 2006.

47. Pearce EN, Pino S, He X, Bazrafshan HR, Lee SL, Braverman LE. Sources of dietary iodine: Bread, cows' milk, and infant formula in the Boston area. J Clin Endocrinol Metab 2004:89:3421-4.

48. Haldimann M, Alt A, Blanc A, Blondeau K. Iodine content of food groups. J Food Comp and Ana 2005:18:461-71.

49. Harris MJ, Jooste PL, Charlton KE. The use of iodised salt in the manufacturing of processed foods in South Africa: Bread and bread pre-mixes, margarine, and flavourants of salty snacks. Int J Food Sci Nutr 2003:54:13-9.

50. Jooste PL. Sources of household salt in South Africa. Asia Pac J Clin Nutr 2005;14:159-62.

51. Mohapatra SSS, Bulliyya G, Kerketta AS, Geddam JB, Acharya AS. Elimination of iodine deficiency disorders by 2000 and its bearing on the people in the district of Orissa, India: A knowledgeattitude-practices study. Asia Pacif J Clin Nutr 2001;10:58-62.

52. Sheikholeslam R. Progress towards elimination of IDD in the Islamic Republic of Iran. A KAP survey of iodized salt consumption. East Medit Health J 1996;2:236-42.

53. Jooste PL, Upson N, Charlton KE. Knowledge of iodine nutrition in the South African adult population. Public Health Nutr 2005;8:382-6.

54. Dunn JT. Seven deadly sins in confronting endemic iodine deficiency, and how to avoid them. J Clin Endocrinol Metab 1996;81:1332-5

55. WHO. The 58th World Health Assembly WHA58.24: Sustaining the elimination of iodine deficiency disorders. Available

http://www.who.int/gb/ebwha/pdf_files/WHA58/WHA58_24-en.pdf (Accessed 7/12/2007).

56. Dunn JT. Complacency: The most dangerous enemy in the war against iodine deficiency. Thyroid 2000;8:681-3. 